\title{
Cortisol to Creatinine Ratio Measurement
}

National Cancer Institute

\section{Source}

National Cancer Institute. Cortisol to Creatinine Ratio Measurement. NCI Thesaurus. Code C106512.

The determination of the ratio of cortisol compared to creatinine present in a sample. The measurement may be expressed as a ratio or percentage. 